\title{
Isolation and Structural Elucidation of an Alkaloid Constituent from the Berries of Brucea Antidysenterica
}

\author{
Tariku Nefo Duke \\ Department of Chemistry, College of natural and computational sciences, University of Wolaita Sodo, P.O. Box, \\ 138, Ethiopia
}

\begin{abstract}
A compound was extracted from the berries of Brucea antidysenterica and identified as Q4 (12(methylamino)tridecane-6-ol). Its structure determination was based on ${ }^{1} \mathrm{H},{ }^{13} \mathrm{C}$ NMR, DEPT-135, IR and LCMS spectral measurements as well as comparison with the literature data.
\end{abstract}

Keywords: Brucea antidysenterica; $\mathrm{NMR}$; $\mathrm{MeOH}$; Structure

DOI: $10.7176 / \mathrm{CPER} / 59-02$

\section{Introduction}

Brucea is a genus of plant in the family Simaroubaceae. It is named for the Scottish scholar and explorer James Bruce [1]. Brucea is a genus of about 10 species occurring in Africa, Asia and Australia [3]. In Ethiopia two species are found and Brucea antidysenterica is the most well known of these. It is shrub or small tree from 10 to $15 \mathrm{~m}$ high, with smooth bark of grey to pale brown color with distribution in tropical Africa: Guinea, Nigeria, Ethiopia, Cameroon, Congo (DRC), Burundi, Sudan, Angola, Zambia and Malawi. The young stems are covered with ferruginous pubescence, leaves are 10-64 $\mathrm{cm}$ long and seed 8-9 $\mathrm{mm}$ long and 5-6 mm wide. Up-land (1400 to $2800 \mathrm{~m}$ ) high evergreen forest and forest margins are very suitable area for the plant [2]. The plant is present at various geographical locations and their presumptive folklore used to prescribe for ascaris and diarrhea. In this paper 1D NMR, IR and LC-MS techniques were used to assign the NMR signals of the isolated sample, including ${ }^{1} \mathrm{H}$ NMR, ${ }^{13} \mathrm{C}$ NMR, DEPT-135, IR and LC-MS spectra.

\section{Materials and Methods \\ Plant Collection and Identification}

The berries of Brucea antidysenterica were collected from southern nations, nationalities, and peoples' region of Ethiopia from Humbo woreda, which is around $337.5 \mathrm{~km}$, south of Addis Ababa. The plant was identified by botanist in the department of biology, Wolaita Sodo University.

\section{Instruments}

${ }^{1} \mathrm{H}$ NMR $\left(400 \mathrm{MHz}, \mathrm{CDCl}_{3}\right)$ and ${ }^{13} \mathrm{C} \mathrm{NMR}\left(100 \mathrm{MHz}, \mathrm{CDCl}_{3}\right)$ spectra were recorded on a Bruker ARX- NMR spectra and with TMS as an internal standard (chemical shifts in $\delta, \mathrm{ppm}$ ). The isolated compound was dissolved in $\mathrm{CDCl}_{3}$ and analyzed with one-dimensional NMR (proton ${ }^{1} \mathrm{H}$, carbon ${ }^{13} \mathrm{C}$ ). ESI- MASS/MS spectra were recorded on an LC-MS mass spectrometer.

\section{Extraction and isolation}

The air-dried berries of Brucea antidysenterica $(200 \mathrm{~g})$ were extracted with one liter of methanol. The $\mathrm{MeOH}$ soluble crude $(9 \mathrm{~g})$ was chromatographed on silica gel $(180 \mathrm{~g})$ using gradient elution with $n$-hexane-EtOAc (100:1 to 1:1). Compound Q4 (35 mg) dark powder was obtained from the $n$-hexane-EtOAc (1:1) fraction.

\section{Results and discussion}

Compound Q4 was obtained as a dark powder from $\mathrm{MeOH}$ extract. Its molecular formula, $\mathrm{C}_{14} \mathrm{H}_{31} \mathrm{NO}$ was determined by negative LC-MS. In the negative LC-MS spectrum, the quasi-molecular ion peak was at $\mathrm{m} / \mathrm{z}$ $229.65[\mathrm{M}-\mathrm{H}]^{-}$.

In the IR $(\mathrm{KBr})$ spectrum the absorption band at $3435 \mathrm{~cm}^{-1}$ due to secondary amine $\left(\mathrm{R}_{2} \mathrm{NH}\right)$ and hydroxyl group. Strong absorption band at $2922 \mathrm{~cm}^{-1}$ and medium absorption band at $1442 \mathrm{~cm}^{-1}$ due to saturated C-H stretching.

The ${ }^{1} \mathrm{H}$ NMR spectrum (table 1) exhibited signal for the presence of a methine bearing of alcohol at $\delta_{\mathrm{H}} 3.21(1 \mathrm{H}, \mathrm{tt}$,$) . Signal at \delta_{\mathrm{H}} 2.79(1, \mathrm{~m})$ shows methine bearing of amine group. Sharp singlet peak at $\delta_{\mathrm{H}} 2.47(3 \mathrm{H})$ is due to $\mathrm{N}$-methyl proton. Signal at $\delta_{\mathrm{H}} 2.55(1 \mathrm{H})$ shows proton of alcohol and signal at $\delta_{\mathrm{H}} 1.90(1 \mathrm{H})$ shows proton of nitrogen. Signals at $\delta_{\mathrm{H}} 1.29-1.44(18 \mathrm{H}, \mathrm{m})$ are due to methylene protons. Signal at $\delta_{\mathrm{H}} 1.10(3 \mathrm{H}, \mathrm{d})$ shows methyl proton attached to carbon bearing amine group and signal $\delta_{\mathrm{H}} 0.96(3 \mathrm{H}, \mathrm{t})$ is due to methyl.

In the ${ }^{13} \mathrm{C}$ NMR spectrum, there were fourteen carbon signals. Signal at $\delta_{\mathrm{C}} 71.9$ represent alcohol bearing methine carbon and signal at $\delta_{\mathrm{C}} 54.7$ shows methine carbon bearing amine group and signal at $\delta_{\mathrm{C}} 34$ is methyl substituent attached to nitrogen. Signals at $\delta_{\mathrm{C}} 22.7,32.15,23,37.9,23.5,30,24.67$ and 37.77 are due to aliphatic 
carbons. Signals at $\delta_{\mathrm{C}} 14.2$ and 21.3 are shows methyl carbons.

The multiplicity of each carbon atom was determined using DEPT-135 experiment, which revealed the presence of three methyl groups (one is attached to nitrogen, one is attached to aliphatic carbon and the other one is attached to methine carbon). Two methine group (one bearing the amine and the other one bearing the alcohol) and the other nine are aliphatic carbons. (Table 1)

Table 1. ${ }^{1} \mathrm{H}-\mathrm{NMR},{ }^{13} \mathrm{C}-\mathrm{NMR}$ and DEPT-135 spectral data of $\mathrm{Q}_{4}$ in $\mathrm{CDCl}_{3}$

\begin{tabular}{|c|c|c|c|}
\hline Position & ${ }^{1}$ H-NMR (ppm) & ${ }^{13} \mathrm{C}-\mathrm{NMR}(\mathrm{ppm})$ & DEPT-135 \\
\hline 1 & $0.98(3 \mathrm{H}, \mathrm{t})$ & 14.2 & $\mathrm{CH}_{3}$ \\
\hline 2 & $1.34(2 \mathrm{H}, \mathrm{tt})$ & 22.7 & $\mathrm{CH}_{2}$ \\
\hline 3 & $1.29(2 \mathrm{H}, \mathrm{tt})$ & 32.15 & $\mathrm{CH}_{2}$ \\
\hline 4 & $1.29(2 \mathrm{H}, \mathrm{tt} \mathrm{J}=5.98 \mathrm{~Hz})$ & 23 & $\mathrm{CH}_{2}$ \\
\hline 5 & $1.44(2 \mathrm{H}, \mathrm{dt})$ & 37.9 & $\mathrm{CH}_{2}$ \\
\hline 6 & $3.21(1 \mathrm{H}, \mathrm{tt})$ & 72 & $\mathrm{CH}$ \\
\hline 7 & $1.44(2 \mathrm{H}, \mathrm{dt})$ & 37.9 & $\mathrm{CH}_{2}$ \\
\hline 8 & $1.29(2 \mathrm{H}, \mathrm{tt})$ & 23.5 & $\mathrm{CH}_{2}$ \\
\hline 9 & $1.29(2 \mathrm{H}, \mathrm{tt})$ & 30 & $\mathrm{CH}_{2}$ \\
\hline 10 & $1.29(2 \mathrm{H}, \mathrm{tt})$ & 24.67 & $\mathrm{CH}_{2}$ \\
\hline 11 & $1.4(2 \mathrm{H}, \mathrm{dt}, \mathrm{J}=4.4 \mathrm{~Hz})$ & 37.77 & $\mathrm{CH}_{2}$ \\
\hline 12 & $2.79(1 \mathrm{H}, \mathrm{m})$ & 54.7 & $\mathrm{CH}$ \\
\hline 13 & $1.1(3 \mathrm{H}, \mathrm{dt})$ & 21.3 & $\mathrm{CH}_{3}$ \\
\hline $\mathrm{N}-\mathrm{CH}_{3}$ & $1.00(3 \mathrm{H}, \mathrm{tt})$ & 34 & $\mathrm{CH}_{3}$ \\
\hline $\mathrm{N}-\mathrm{H}$ & $1.90(1 \mathrm{H})$ & - & - \\
\hline $\mathrm{O}-\mathrm{H}$ & $2.55(1 \mathrm{H})$ & - & - \\
\hline
\end{tabular}

All chemical shift data in the 1D-NMR, IR and LC-MS spectra closely matched the tentative proposed structure for the compound Q4(12-(methylamino)tridecane-6-ol). (See Fig 1)<smiles>CCCCCC(O)CCCCCC(C)NC</smiles>

Fig. 1 The structure of compound Q4

\section{Conclusion}

This work resulted in the isolation of one new compound that is not isolated from the plant in previous study, the compound was Q4 (12-(methylamino)tridecane-6-ol). The structure of the compound was characterized on the basis of spectral data (1H-NMR, ${ }^{13} \mathrm{C}-\mathrm{NMR}$, DEPT-135, IR and LC-MS) as well as comparison with the literature data.

\section{Acknowledgement}

This study was supported by a grant from Wolaita Sodo University.

\section{References}

[1] Kulip, Julius; Wong, K. M. (1995). "Brucea javanica (L.) Merr." (PDF). In Soepadmo, E.; Wong, K. M. Tree Flora of Sabah and Sarawak. (free online from the publisher, lesser resolution scan PDF versions). 1. Forest Research Institute Malaysia. p. 429. ISBN 983-9592-34-3. Retrieved 3 Oct 2016.

[2] Brian, S., 2000. Simaroubaceae. Flora of Tropical East Africa. Beentje, H. J., Smith, S. A. L., Whitehouse, C. M., (Edts), Rotterdam/Brook field, 6-10.

[3] Hedberg, I., Edvans, S., 1989. Simaroubaceae. Flora of Ethiopia 3. Uppsala, 437- 441. 